\title{
Growth hormone treatment strategies in assisted reproduction for the poor responder patients
}

K. V.Ob'edkova ${ }^{1,2}$, A.M. Gzgzyan ${ }^{1,2}$, D. A. Niauri ${ }^{1,2}$, L. Kh. Dzhemlikhanova', ${ }^{1,2}$ I. Yu. Kogan ${ }^{1,2}$, I. O. Krikheli' ${ }^{2}$ I. D. Mekina ${ }^{2}$, E. A. Lesik', E. M. Komarova ${ }^{2}$, M. A. Mazilina ${ }^{1,2}$

${ }^{1}$ St. Petersburg State University,

7-9, Universitetskaya nab., St. Petersburg, 199034, Russian Federation

2 Department of Assisted Reproduction Technologies,

FSBI D. O. Ott Research Institute of Obstetrics, Gynecology and Reproductology,

3, Mendeleevskaya liniya, St. Petersburg, 199034, Russian Federation

For citation: Ob’edkova K.V., Gzgzyan A.M., Niauri D.A., Dzhemlikhanova L.Kh., Kogan I.Yu., Krikheli I. O., Mekina I.D., Lesik E. A., Komarova E. M., Mazilina M. A. Growth hormone treatment strategies in assisted reproduction for the poor responder patients. Vestnik of Saint Petersburg University. Medicine, 2019, vol. 14, issue 2, pp. 132-139. https://doi.org/10.21638/spbu11.2019.205

The goal of the study was to estimate the efficacy of growth hormone $(\mathrm{GH})$ co-treatment to the antagonist protocol in IVF/ ICSI cycles in poor responders. A prospective observational study involved 75 patients. All patients underwent standard antagonist protocol with or without $\mathrm{GH}$ co-treatment. GH additional was given a daily subcutaneous injection of $1.33 \mathrm{mg}$ (equivalent to $4 \mathrm{IU}$ ) of GH from day 1 of ovarian stimulation until the day of human chorionic gonadotropin (hCG). Concentrations of GH, insulin-like growth factor I (IGF-I) and IGF binding protein-3 (IGFBP-3) in serum and follicular fluid were analyzed. The GH co-treatment significantly lowered effective dose of gonadotropins, duration of stimulation, IGFBP-3 level in serum and follicular fluid day of oocytes retrieval. The number of oocytes recovered, metaphase II stage (MII) oocytes, 2 pronucleus ( 2 pn) zygote, good-quality transferred embryos were significantly higher in the $\mathrm{GH}+$ group. Only patients $\mathrm{GH}+$ group became pregnant. Positive correlation was found between IGF-I level in follicular fluid, dynamics of IGFBP-3 level changes during stimulation protocol and number of good-quality transferred embryos in the $\mathrm{GH}+$ group. GH administration in IVF/ICSI cycles for poor responders raises ovarian sensitivity to the gonadotropin exogenous influence, this way, increasing number of high-quality embryos and the probability of pregnancy.

Keywords: growth hormone, poor ovarian response, in vitro fertilization (IVF), assisted reproductive technologies (ART).

\section{Introduction}

The prognosis for treatment by IVF is highly dependent upon ovarian response and the quality of oocytes retrieved, with both factors deciding the number of good quality embryos that will generated. Poor response to ovarian stimulation (POR) is not a rare event in assisted reproduction (ART); its reported frequency in IVF cycles varies from 9 to $30 \%$ between investigators [1].

(C) Санкт-Петербургский государственный университет, 2019 
POR remains a problem in IVF cycles until today. Despite the use of different treatment strategies, clinical pregnancy rate is low in poor responders. It often leads to couples giving up the treatment or using oocyte donation. There are numerous strategies that have been proposed to improve the outcome in the poor responder women despite their limited successes. Meta-analysis by Kyrou et al. [2] suggested that, out of all of the recently proposed protocol alterations, GH addition significantly increased the IVF success rate.

In this research, we aimed to estimate the efficacy of GH co-treatment to the antagonist protocol in IVF/ ICSI cycles in poor responders.

\section{Methods}

A prospective observational study was performed at ART department of FSBSI D.O. Ott Research Institute of Obstetrics, Gynecology and Reproductology, St. Petersburg, Russian Federation between September 2015 and January 2017.

The research included 75 women with POR. Poor responders were defined by the Bologna consensus criteria [1]. At least two of the following three features must be present:

1. The risk factors for POR are represented by maternal age $\geq 40$ years and by all the known genetic or acquired conditions possibly linked to a reduced amount of resting follicles;

2. A POR is represented by a cycle cancelled (following the development of less than three growing follicles) or the collection of less than four oocytes in response to an ovarian stimulation protocol of at least $150 \mathrm{IU}$ follicle-stimulating hormone (FSH) per day;

3. An abnormal ovarian reserve test (i.e. antral follicle count, 5-7 follicles or antiMüllerian hormone (AMH), 0.5-1.1 ng/ml).

Two episodes of POR after maximal stimulation are sufficient to definea patient as poor responder in the absence of advanced maternal age or abnormal ovarian reserve test.

Exclusion criteria for the research were a day $3 \mathrm{FSH}>20 \mathrm{IU} / \mathrm{l}$, body mass index $(\mathrm{BMI}) \geq 35 \mathrm{~kg} / \mathrm{m}^{2}$ and severe male factor infertility. Written informed consent was obtained from all the couples before IVF treatment.

Study population was divided to two groups. 35 patients were allocated to $\mathrm{GH}$ cotreatment group ( $\mathrm{GH}+$ group), the other 40 were allocated to standard antagonist protocol without $\mathrm{GH}$ administration (GH- group).

All patients underwent gonadotropin releasing hormone $(\mathrm{GnRH})$ antagonist conventional ovarian stimulation with recombinant or menopausal gonadotropins. GH cotreatment was given a daily subcutaneous injection of $1.33 \mathrm{mg}$ (equivalent to $4 \mathrm{IU}$ ) of GH (Norditropin pen, Novo Nordisk, Denmark) from day 1 of ovarian stimulation until the day of hCG (Fig. 1).

Baseline serum concentrations of gonadotropins and ovarian hormones (estradiol (E2), prolactin (Prol), AMH, FSH and luteinizing hormone (LH)) were measured on day 3 of pretreatment cycle.

The serum GH, IGF-I and IGFBP-3 levels were analyzed on day 1 of ovarian stimulation and day of oocytes retrieval. Submitted markers were also determined in follicular fluid. Follicular fluid was obtained from during oocyte pick up; only samples not contaminated with blood and which didn't contain cumulus-oocyte-complexes were used for 
Standard antagonist protocol with GH co-treatment

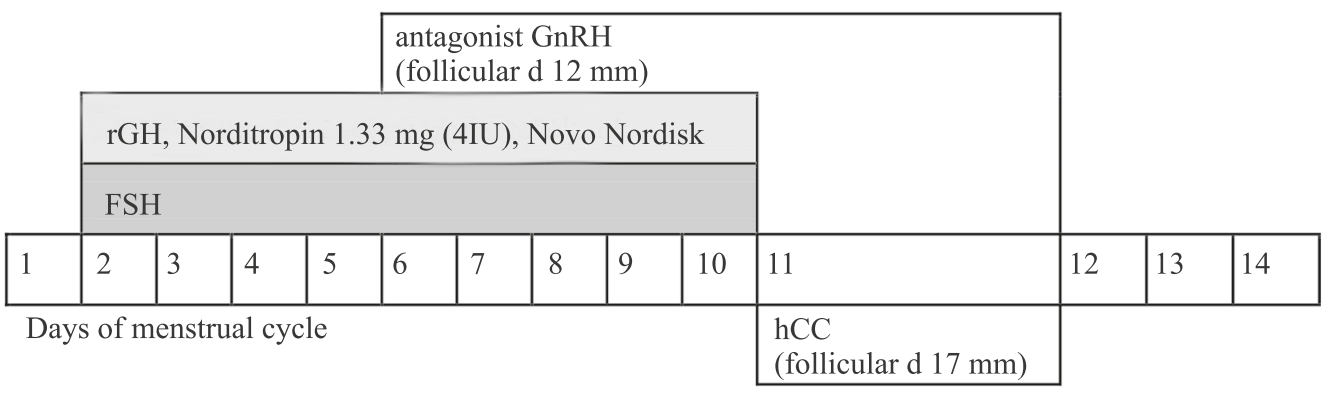

Standard antagonist protocol without GH co-treatment

\begin{tabular}{|c|c|c|c|c|c|c|c|c|c|c|c|c|c|}
\hline & & & & & & & $\mathrm{C}$ & & & & & & \\
\hline & 2 & 3 & 4 & 5 & 6 & 7 & 8 & 9 & 10 & 11 & 12 & 13 & 14 \\
\hline & & & & & & & & & & $\begin{array}{l}\text { hCC } \\
\text { (follicular d } 17 \mathrm{~mm} \text { ) }\end{array}$ & & & \\
\hline
\end{tabular}

Fig. 1. Ovulation stimulation protocol

the analysis. GH, IGF-I and IGFBP-3 concentrations in serum and follicular fluid were measured by enzyme immunoassay (ELISA) (Mediagnost, Germany).

Statistical analysis was performed using the application package "STATISTICA v 10.0 for Windows" (Statsoft Inc., USA). Data were examined by non-parametric analysis. Median and quartiles (Me(LQ;UQ)) of distribution were determined for each continuous variable. Hormonal and cycle characteristics were compared by using the Mann-Whitney $\mathrm{U}$ test, the Wilcoxon test where appropriate. Non-parametric ANOVA was used to compare concentration of GH, IGF-I and IGFBP-3 in serum and follicular fluid. Association between two variables was estimated using Spearman correlation coefficient and gamma correlation coefficient. The significance level (p) was set at 0.05 for all statistical tests.

\section{Results}

Patients in the two groups did not differ significantly in age and gynecological background (Table 1). The baseline FSH level was significantly higher and the AMH level was significantly lower in the GH co-treatment cycle (Table 2). There were no significant differences in the serum GH, IGF-I and IGFBP-3 concentrations between the two groups (Fig. 2-4).

The GH concentration in follicular fluid and serum on the day of oocytes retrieval was significantly higher (Fig. 2) and IGFBP-3 level in this biological fluids was significantly lower (Fig. 4) in the GH+ group as compared with the GH-group. Moreover, IGF-I level in serum on the day of oocytes retrieval was significantly higher in the GH co-treatment cycle (Fig. 3). 
Table 1. Structure of gynecological diseases

\begin{tabular}{|c|c|c|c|c|c|c|c|}
\hline \multirow{2}{*}{\multicolumn{2}{|c|}{ Characteristic }} & \multicolumn{2}{|c|}{$\mathrm{GH}+$ group, $\mathrm{n}=35$} & \multicolumn{2}{|c|}{ GH- group, $n=40$} & \multirow{3}{*}{$\begin{array}{c}\mathrm{X}^{2} \\
-\end{array}$} & \multirow{3}{*}{$\frac{\text { p-value }}{-}$} \\
\hline & & \multirow{2}{*}{$\begin{array}{c}\text { Abs. } \\
-\end{array}$} & \multirow{2}{*}{$\%$} & \multirow{2}{*}{$\begin{array}{c}\text { Abs. } \\
-\end{array}$} & \multirow{2}{*}{$\frac{\%}{-}$} & & \\
\hline \multirow{4}{*}{ Endometriosis } & I st. & & & & & & \\
\hline & II st. & 5 & 14,29 & 5 & 12,5 & 1,418 & $>$ \\
\hline & III st. & 1 & 2,86 & 3 & 7,5 & 0,576 & $>$ \\
\hline & IV st. & 11 & 31,43 & 7 & 17,5 & 0,212 & $>$ \\
\hline \multicolumn{2}{|l|}{ Adenomyosis } & 6 & 20 & 5 & 12,5 & 0,058 & $>$ \\
\hline \multicolumn{2}{|l|}{ Myoma } & 8 & 22,86 & 5 & 12,5 & 0,768 & $>$ \\
\hline \multicolumn{2}{|c|}{ Ovarian dysfunction } & 31 & 88,57 & 32 & 80 & 0,3605 & $>$ \\
\hline \multicolumn{2}{|c|}{ Chronic salpingo-oophoritis } & 20 & 57,14 & 32 & 80 & 3,575 & $>$ \\
\hline
\end{tabular}

Table 2. Hormonal characteristics

\begin{tabular}{|c|c|c|c|c|c|c|c|c|}
\hline \multirow{2}{*}{ Characteristic } & \multicolumn{3}{|c|}{$\mathrm{GH}+$ group, $\mathrm{n}=35$} & \multicolumn{3}{|c|}{ GH- group, $n=40$} & \multirow{2}{*}{$\begin{array}{c}\text { Mann - } \\
\text { Whitney } \\
\text { U-test }\end{array}$} & \multirow{2}{*}{ p-value } \\
\hline & $\mathrm{Me}$ & LQ & UQ & $\mathrm{Me}$ & LQ & UQ & & \\
\hline FSH, IU/1 & 12,5 & 9,2 & 14,9 & 7,15 & 5,81 & 8,295 & 188 & 0,000001 \\
\hline LH, IU/l & 5,7 & 3,55 & 7,25 & 4,535 & 3,575 & 5,61 & 672,5 & 0,774115 \\
\hline $\mathrm{AMH}, \mathrm{ng} / \mathrm{ml}$ & 0,32 & 0,21 & 0,5 & 0,75 & 0,655 & 0,85 & 648,5 & 0,588066 \\
\hline $\mathrm{E} 2, \mathrm{pg} / \mathrm{ml}$ & 138 & 103 & 187 & 142,6 & 100,25 & 181 & 95,5 & 0,254103 \\
\hline Prol, mME/ml & 324 & 245,36 & 369,23 & 291,6 & 257,9 & 348,91 & 113,5 & 0,648383 \\
\hline
\end{tabular}
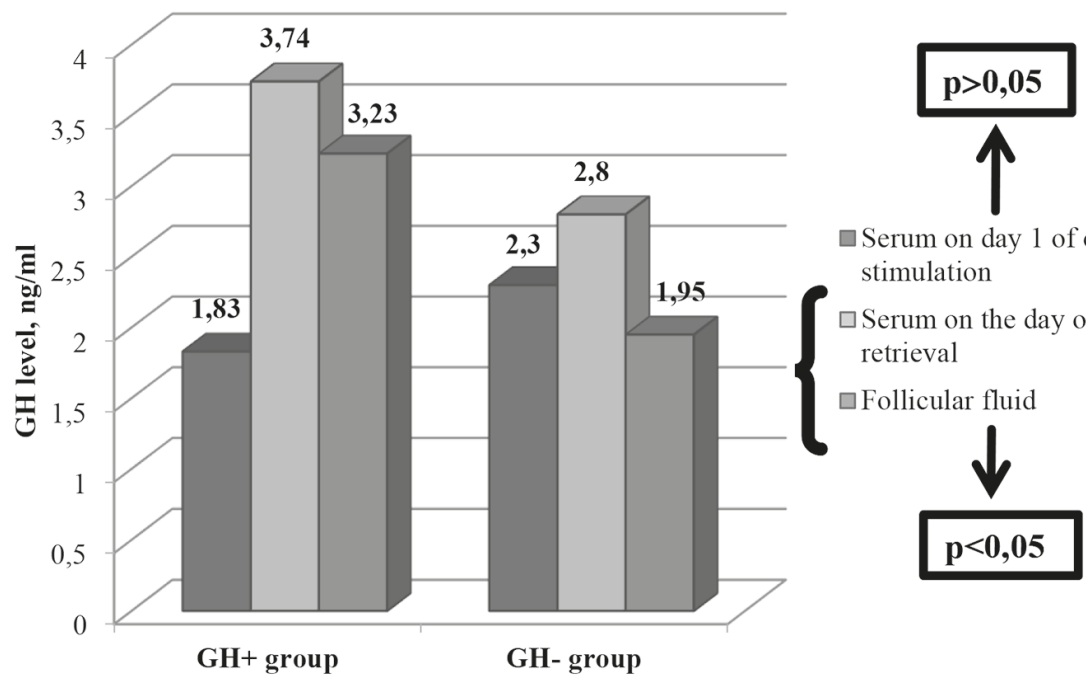

$\square$ Serum on day 1 of ovarian stimulation

$\square$ Serum on the day of oocytes retrieval

$\square$ Follicular fluid

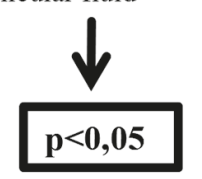

Fig. 2. Level GH in serum and follicular fluid 


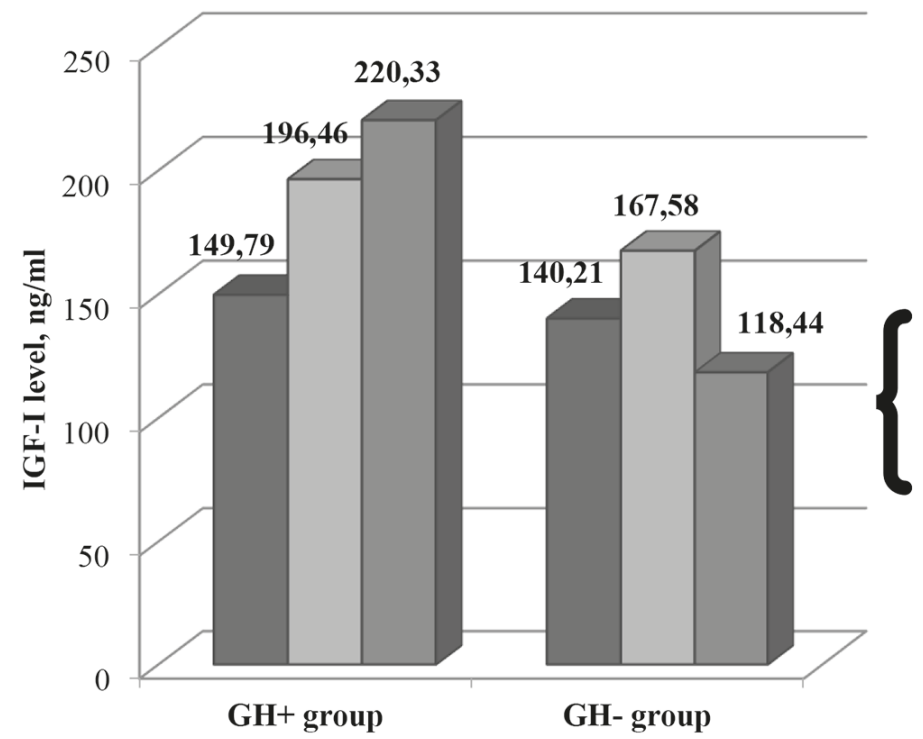

$p>0,05$

个

$\square$ Serum on day 1 of ovarian stimulation

$\square$ Serum on the day of oocytes retrieval

$\square$ Follicular fluid

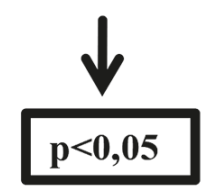

Fig. 3. Level IGF-I in serum and follicular fluid

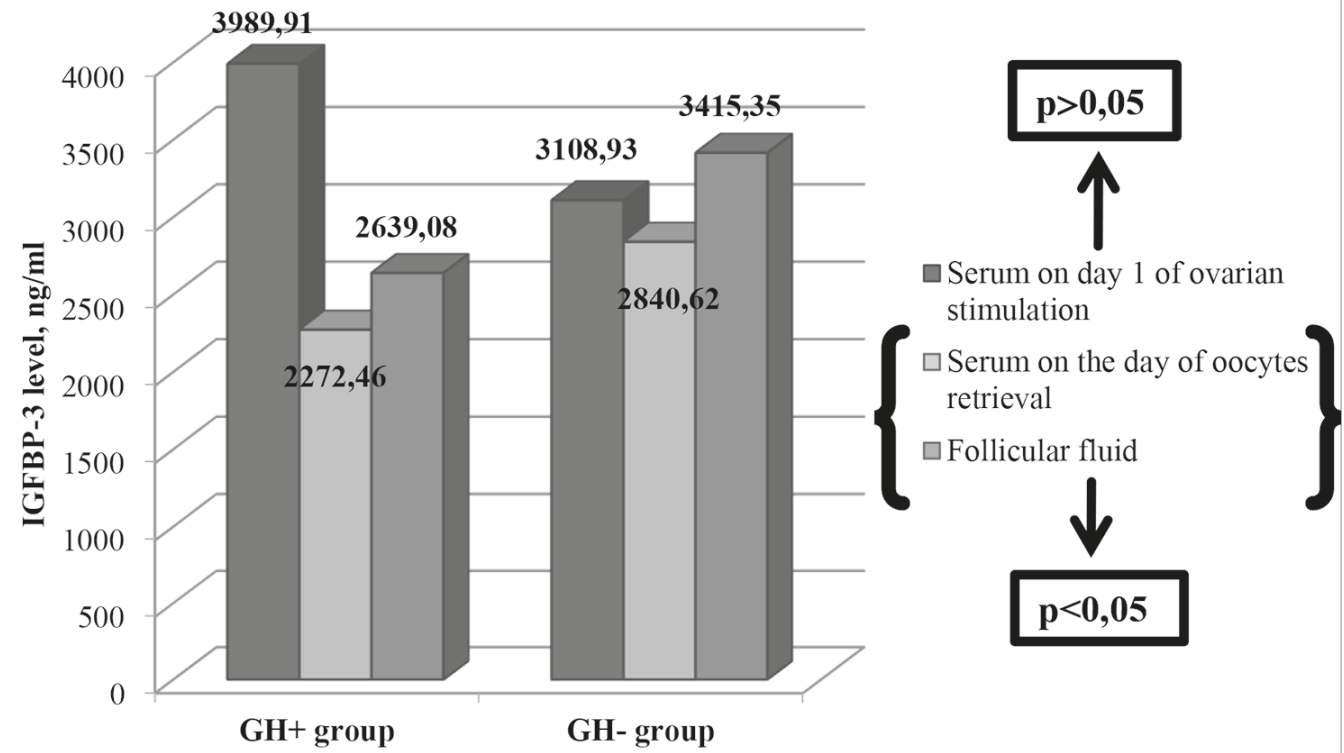

Fig. 4. Level IGFBP-3 in serum and follicular fluid

The serum GH concentration was significantly increased on the day of oocytes retrieval than on the first day of stimulation protocol $(\mathrm{W}=21, \mathrm{p}=0.015)$ in the $\mathrm{GH}+$ group. Additionally, IGFBP-3 level was significantly diminished in follicular fluid ( $\mathrm{W}=24$, $\mathrm{p}=0.023)$ and serum on the day of oocytes retrieval $(\mathrm{W}=10, \mathrm{p}=0.003)$ than on the first day of stimulation protocol in the GH+ group.

Total dose of gonadotropins was not different between the two groups. However, effective dose of gonadotropins, duration of stimulation were significantly lower in the GH+ 
group as compared with the GH- group. The number of follicles on the day of hCG, oocytes retrieved, MII oocytes, 2 pn zygote, good-quality transferred embryos were significantly higher in the $\mathrm{GH}+$ group as compared with the GH- group (Table 3 ).

Table 3. Cycle characteristics

\begin{tabular}{|c|c|c|c|c|c|c|c|c|}
\hline \multirow{2}{*}{ Characteristic } & \multicolumn{3}{|c|}{$\mathrm{GH}+$ group, $\mathrm{n}=35$} & \multicolumn{3}{|c|}{ GH- group, $n=38$} & \multirow{2}{*}{$\begin{array}{c}\text { Mann- } \\
\text { Whitney } \\
\text { U-test }\end{array}$} & \multirow{2}{*}{ p-value } \\
\hline & $\mathrm{Me}$ & LQ & UQ & $\mathrm{Me}$ & LQ & UQ & & \\
\hline $\begin{array}{l}\text { Starting dose of } \\
\text { gonadotropins, IU }\end{array}$ & 300 & 225 & 300 & 300 & 237,5 & 300 & 428,5 & 0,1987 \\
\hline $\begin{array}{l}\text { Total dose of } \\
\text { gonadotropins, IU }\end{array}$ & 2250 & 1800 & 3000 & 2543,75 & 1850 & 3425 & 226 & 1,0 \\
\hline $\begin{array}{l}\text { Effective dose of } \\
\text { gonadotropins, IU }\end{array}$ & 750 & 500 & 1325 & 1321,88 & 712,5 & 2100 & 578,5 & 0,008 \\
\hline $\begin{array}{l}\text { Duration of } \\
\text { stimulation, days }\end{array}$ & 8 & 7 & 10 & 9 & 8 & 10 & 27,5 & 0,0004 \\
\hline $\begin{array}{l}\text { No. of follicles on } \\
\text { the day of hCG }\end{array}$ & 4 & 3 & 7 & 3 & 2 & 4 & 209,5 & 0,045 \\
\hline $\begin{array}{l}\text { No. of oocytes } \\
\text { recovered }\end{array}$ & 3 & 2 & 5 & 2 & 1 & 3 & 317 & 0,0005 \\
\hline No. of MII oocytes & 4 & 3 & 6 & 1 & 0 & 2 & 292,5 & 0,043 \\
\hline No. of $2 \mathrm{p}$ zygote & 2 & 1 & 4 & 1 & 0 & 2 & 195 & 0,0004 \\
\hline \multicolumn{9}{|c|}{ Day 3 from fertilization } \\
\hline $\begin{array}{l}\text { No. of transferred } \\
\text { embryos }\end{array}$ & 2 & 1 & 2 & 1 & 1 & 2 & 55,5 & 0,659 \\
\hline $\begin{array}{l}\text { No. of good- } \\
\text { quality transferred } \\
\text { embryos }\end{array}$ & 2 & 1 & 2 & 1 & 0 & 1 & 6 & 0,0004 \\
\hline \multicolumn{9}{|c|}{ Day 4 from fertilization } \\
\hline $\begin{array}{l}\text { No. of transferred } \\
\text { embryos }\end{array}$ & 2 & 2 & 2 & 2 & 1 & 2 & 3 & 0,7728 \\
\hline $\begin{array}{l}\text { No. of good- } \\
\text { quality transferred } \\
\text { embryos }\end{array}$ & 2 & 1 & 2 & 0 & 0 & 0 & 0 & 0,0489 \\
\hline
\end{tabular}

Positive correlation was found between IGF-I level in follicular fluid and number of good-quality transferred embryos $(\gamma=0.5, \mathrm{p}=0.048)$; dynamics of IGFBP-3 level changes in follicular fluid and serum on the first day of stimulation protocol and number of oocytes retrieved $(\gamma=0.53, \mathrm{p}=0.007)$, number of fertilyzed oocytes $(\mathrm{R}=0.66, \mathrm{p}=0.005)$, number of good-quality transferred embryos $(\gamma=0.72, p=0.004)$ in the $\mathrm{GH}+$ group.

Two patients in the $\mathrm{GH}+$ group and seventeen patients in the $\mathrm{GH}$ - group didn't reach embryo transfer stage, but cycle cancellation rate was significantly higher in the GH- 
group (Fisher's exact test $0.01 ; \mathrm{p}<0.05$ ). The reasons for cancellation in the $\mathrm{GH}$ - group were absence of cumulus-oocyte-complexes retrieved in five patients, total fertilization failure in eleven patients, and no-cleavage in one patient.

Only patients $\mathrm{GH}+$ group became pregnant; clinical pregnancy rate was $24.24 \%$. Probability of pregnancy was significantly increased in the GH+ group as compared with the $\mathrm{GH}$ - group $(\mathrm{OR}(95 \% \mathrm{CI})=9.1(1.034-80.093), \mathrm{p}<0.05)$.

No side effect was seen in any of the patients.

\section{Discussion}

Over 25 years ago, Owen et al. [3] concluded that GH co-treatment improves the ovarian response to ordinary ovarian stimulation protocols in sub-optimal responders. This conclusion was supported studies by Homburg et al. [4] demonstrating that GH administration raises ovarian sensitivity to the gonadotropins influence. GH mRNA and immunoreactivity are discovered in ovarian stromal and follicular tissue from human [5]. GH gene expression is initiated early in follicular development in humans, since GH mRNA and immunoreactivity were found in the oocyte cytoplasm and the granulosa cells of fetal primordial follicles [6]. In this research, effective dose of gonadotropins, duration of stimulation were significantly lower in the GH co-treatment. Furthermore, a study by Kucuk et al. [7] observed an improved ovarian response as well as increased ART success.

Despite numerous more recent studies, the GH co-treatment in IVF/ICSI cycles for poor responders remains controversial [8]. The problem is supposed to associate with the definition of a poor responder, underpowered statistical analysis, the pooling of patients with diverse risk factors such as age, and heterogeneous protocols of GH administration, ovarian stimulation, and luteal support [9]. However, most studies conclude that the outcomes improved by GH are generally those reflecting increased oocyte quality, such as the number of MII stage recovered, the fertilization rate [7], the number of embryos reaching the transfer stage [9], the pregnancy rate [10] and the rate of live births [11]. This research showed that GH co-treatment to the antagonist protocol in poor responders undergoing IVF/ICSI cycles significantly improved the number of oocytes collected, MII oocytes retrieved, 2 pn zygote and good-quality transferred embryos. Moreover, adjuvant GH therapy seems to enhance both the fertilization rate and the quality of the resulting embryos, as indicated by improved blastomere uniformity and cleavage rate and decreased apoptosis [12].

$\mathrm{GH}$ is reported to modulate the action of FSH on granulosa cells by up-regulating the local synthesis of insulin-like growth factor-I. The IGF-I amplifies the effect of gonadotropin action at the level of both the granulosa and theca cell [13;14]. It was found, that follicular GH levels were positively correlated with IVF success [15], and follicles containing higher GH levels gave rise to the highest quality embryos [16]. In this study, positive correlation was found between IGF-I level in follicular fluid and number of good-quality transferred embryos; dynamics of IGFBP-3 level changes in follicular fluid and serum on the first day of stimulation protocol and number of oocytes retrieved, number of fertilyzed oocytes, number of good-quality transferred embryos in the GH+ group.

Most systematic reviews and meta-analyzes suggested that GH addition significantly increased clinical pregnancy rate and live birth rates $[8 ; 9 ; 11]$. In this study, probability of pregnancy was significantly increased in the $\mathrm{GH}+$ group as compared with the $\mathrm{GH}$ - group. 
Potential side-effects observed with GH treatment include increased fluid retention, resulting in edema, headaches, and/or joint pain, neoplasms, cerebrovascular events, and altered glucose metabolism [17]. However, GH co-treatment in IVF/ ICSI cycles is not associated with any adverse events except for slight edema. In this study, no side effect was seen in any of the patients.

In conclusion, GH administration in IVF/ICSI cycles for poor responders raises ovarian sensitivity to the gonadotropin exogenous influence, this way, increasing number of oocytes collected, MII oocytes retrieved, fertilization rate, number of high-quality embryos and the probability of pregnancy. The effectiveness of overcoming infertility by IVF in patients with POR in terms of adjuvant GH therapy depends on the dynamics of increasing IGF-I concentration and the dynamics of decreasing IGFBP-3 concentration in blood serum and follicular fluid during ovarian stimulation. Taking into consideration small sample of women examined, it is necessary to continue the study of GH use effectiveness and safety for the recommendation of its wide administration in clinical practice.

\section{Declaration of interest}

The authors report that they have no conflict of interest. No funding was required for this study.

\section{References}

1. Ferraretti A.P., La Marca A., Fauser B. C. J. M., Tarlatzis B., Nargund G., Gianaroli L. ESHRE consensus on the definition of "poor response" to ovarian stimulation for in vitrofertilization: the Bologna criteria. Hum. Reprod., 2011, vol. 26, pp. 1616-1624.

2. Kyrou D., Kolibianakis E. M., Venetis C. A., Papanikolaou E. G., Bontis J., Tarlatzis B. C. How to improve the probability of pregnancy in poor responders undergoing in vitro fertilization: a systematic review and meta-analysis. Fertil. Steril., 2009, vol. 91, pp. 749-766.

3. Owen E.J., West C., Mason B.A., Jacobs H.S. Cotreatment with growth hormone of sub-optimal responders in IVF-ET. Hum. Reprod., 1991, vol. 6, pp. 524-528.

4. Homburg R., Eshel A., Abdalla H. I., Jacobs H.S. Growth hormone facilitates ovulation induction by gonadotrophins. Clinical Endocrinology,1988, vol. 29, pp. 113-117.

5. Schwarzler P., Untergasser G., Hermann M. et al. Selective growth hormone/placental lactogen gene transcription and hormone production in pre- and postmenopausal human ovaries. The Journal of Clinical Endocrinology and Metabolism, 1997, vol. 82, pp. 3337-3341.

6. Abir R. Garor R., Felz C., Nitke S., Krissi H., Fisch B. Growth hormone and its receptor in human ovaries from fetuses and adults. Fertil. Steril., 2008, vol. 90, pp. 1333- 1339.

7. Kucuk T., Kozinoglu H., Kaba A. Growth hormone cotreatment within a GnRH agonist long protocol in patients with poor ovarian response: a prospective, randomized, clinical trial. Journal of Assisted Reproduction and Genetics, 2008, vol. 25, pp. 123-127.

8. De Ziegler D., Streuli I., Meldrum D. R., Chapron C. The value of growth hormone supplements in ART for poor ovarian responders. Fertil. Steril., 2011, vol. 96, pp. 1069-1076.

9. Kolibianakis E.M., Venetis C.A., Diedrich K., Tarlatzis B.C., Griesinger G. Addition of growth hormone to gonadotrophins in ovarian stimulationof poor responders treated by in-vitro fertilization: a systematic review and meta-analysis. Hum. Reprod., 2009, vol. 15, pp. 613-622.

10. Hazout A., Junca A.M., Menezo Y., de Mouzon J., Cohen-Bacrie P. Effect of growth hormone on oocyte competence in patients with multiple IVF failures. Reproductive BioMedicine Online, 2009, vol. 18, pp. 664-670.

11. Duffy J.M.N., Ahmad G., Mohiyiddeen L., Nardo L.G., Watson A. Growth hormone for in vitro fertilization (Review). Cochrane Database Syst Rev., 2010, no. 1, p. CD000099.

12. Rajesh H., Yong Y. Y., Zhu M., Chia D., Yu S. L. Growth hormone deficiency and supplementation at in-vitro fertilization. Singapore Medical Journal, 2009, vol. 48, pp. 514-518. 
13. Hsu C., Hammond J. Concomitant effects of growth hormone on secretion of insulin-like growth factor I and progesterone by cultured porcine granulosa cells in vitro. Endocrinology, 1988, vol. 120, pp. 198-207.

14. Barecca A., Artini P. G., Del Monte P., Ponzani P., Pasquini P., Cariola G. In vivo and in vitro effect of growth hormone on estradiol secretion by granulosa cells. J. Clin. Endocrinol. Metab., 1993, vol. 77, pp. 61-67.

15. Tesarik J., Hazout A., Mendoza C. Improvement of delivery and live birth rates after ICSI in women aged $>40$ years by ovarian co-stimulation with growth hormone. Hum. Reprod., 2005, vol. 20, pp. 2536-2541.

16. Mendoza C., Ruiz-Requena E., Ortegaetal E. Follicular fluid markers of oocyte developmental potential. Hum. Reprod., 2002, vol. 17, pp. 1017-1022.

17. Kokshoorn N.E., Biermasz N. R., Roelfsema F., Smit J. W. A., Pereira A. M., Romijn J. A. GH replacement therapy in elderly GH-deficient patients: a systematic review. European Journal of Endocrinology, 2011, vol. 164, pp. 657-665.

Authors' information:

Ksenia V. Ob’edkova - MD, PhD; obedkova_ks@mail.ru

Alexandr M. Gzgzyan — MD, PhD; agzgzyan@mail.ru

Dariko A. Niauri - MD, PhD, Professor; d.niauri@mail.ru

Liailia Kh. Dzhemlikhanova - MD, PhD; dzhemlikhanova_l@mail.ru

Igor Yu. Kogan - MD, PhD, Professor; ikogan@mail.ru

Inna O. Krikheli — MD, PhD; ikrekhily@gmail.com

Irina D. Mekina - PhD; ovrt@ott.ru

Elena A. Lesik - PhD; ovrt@ott.ru

Evgenia M. Komarova - PhD; ovrt@ott.ru

Maria A. Mazilina _ MSc; ovrt@ott.ru 